\title{
REFRACTURE OF THE FOREARM IN CHILDREN
}

\author{
N. SCHWARZ, S. PIENAAR, A. F. SCHWARZ, M. JELEN, \\ W. STYHLER, J. MAYR
}

From the Trauma Hospital Meidling, Vienna, Austria

Tn a retrospective study we reviewed 28 refractures tof the forearm in children, which occurred at a mean of 14 weeks after conservative treatment of the primary fracture. The cause for the refracture was incomplete healing of a primary greenstick fracture in 21 cases $(84 \%)$. Twenty-two recurrent fractures were treated conservatively, but two had a second refracture.

Fifteen patients were followed for over two years. Definitive angulation of more than $10^{\circ}$ caused a deficit of forearm rotation.

To prevent refracture of the forearm in children, complete and circular consolidation of the primary fracture must be guaranteed.

J Bone Joint Surg [Br] 1996;78-B:740-4.

Received 29 January 1996; Accepted after revision 4 April 1996

In children, refracture is a relatively common complication of a forearm fracture, seen in about $5 \%$ of cases (Tischer 1982). There are few published reports: we could find only four papers which dealt specifically with this subject (Arunachalam and Griffiths 1975; Filipe, Dupont and Carlioz 1979; Gruber and von Laer 1979; Lascombes et al 1988). These discussed the causes of refracture, but gave little information about treatment and outcome. Lascombes et al (1988) suggested that such fractures should be treated "more vigorously than the primary fracture", but provided no details or results.

Refracture is thought to be caused by repetition of the same injury (Arunachalam and Griffiths 1975), by impaired

N. Schwarz, MD, Professor of Traumatology

S. Pienaar, MD, Resident

Trauma Hospital Meidling, Kundrastrasse 37, A-1120 Vienna, Austria.

A. F. Schwarz, MD, Resident

Trauma Hospital, Dr. F. Rehrl Platz 5, A-5020 Salzburg, Austria.

M. Jelen, MD, Trauma Surgeon

Trauma Hospital, Waidmannsdorferstrasse 65, A-9020 Klagenfurt, Austria.

W. Styhler, MD, Trauma Surgeon

Trauma Hospital, Blaumauerplatz 1, A-4020 Linz, Austria.

J. Mayr, MD, Associate Professor of Paediatric Surgery

University of Graz, Auenbruggerplatz 34, A-8036 Graz, Austria.

Correspondence should be sent to Dr N. Schwarz.

(C)1996 British Editorial Society of Bone and Joint Surgery 0301-620X/96/51257\$2.00 local perfusion (Frinta 1957), by removal of plaster too early (Lascombes et al 1988; Ogden 1990), by poor cast technique (Hager, Ploberger and Povacz 1989), or by inadequate reduction (Gruber and von Laer 1979). The most convincing theory is based on the observation that most refractures occur after greenstick shaft fractures which have not fully healed because of persistent angulation (Filipe et al 1979; Gruber and von Laer 1979). Incomplete consolidation is thought to reduce the strength even months after the original fracture. Our review aimed to test the hypothesis that incomplete consolidation was an important cause of refracture of the forearm in children, and to compile data concerning treatment and outcome.

\section{PATIENTS AND METHODS}

Our retrospective multicentre study involved a total of 28 patients from nine hospitals. They were selected on the basis of the diagnosis of a refracture, and not on the forearm fracture. No conclusion can be drawn therefore on the frequency of refracture.

We defined refracture as one which is at least partly in an older fracture line, with an obvious causal connection. In a greenstick fracture in diaphyseal cortical bone, one cortex is ruptured transversely and the opposite cortex is bent, but not broken. The cortical fracture commonly ends in fissures parallel to the long axes of both proximal and distal fragments (Figs 1 and 2).

Primary fracture. There were 23 boys and 5 girls aged 4 to 13 years: the left side was involved in 16, the right side in 12 cases. Four patients had incomplete radiological records of the primary fracture; these are included only in the analysis of refractures.

Of 24 sets of primary radiographs, 16 showed that both the radius and ulna had been fractured and six showed only radial and two only ulnar fractures. There were greenstick fractures of 16 ulnae and 15 radii, with complete fractures in two ulnae and six radii and a torus fracture in one radius (Table I). Sixteen ulnar and 15 radial fractures were in the middle third of the shaft.

The primary fractures had been treated in an aboveelbow cast for 3 weeks (2), 4 weeks (6), 5 weeks (5), 6 weeks (11), and 7 weeks (1). In three patients the duration was not recorded.

The primary fracture was followed up for less than six months in six patients, for six to 12 months in two, for 12 to 24 months in five, and for over 24 months in 15 patients up to a maximum of 26 years. 

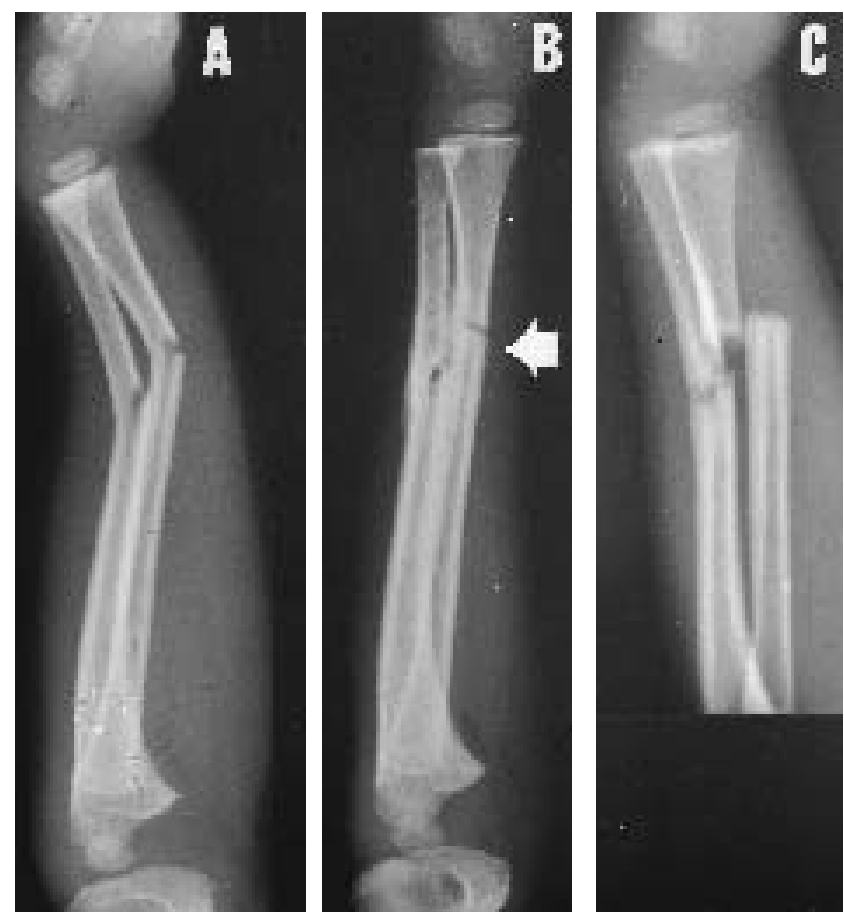

Fig. 1

A five-year-old boy had plaster fixation of a greenstick fracture of the forearm (A). There was a marked fracture gap on the volar site of the radius and ulna six weeks after injury (B arrow). Refracture 16 weeks after injury was caused by a fall in the street (C).
Refractures. Eighteen of the 24 patients had had a greenstick fracture of one or both forearm bones, and in all but one there was persistent angulation, usually in a dorsal direction with incomplete consolidation of the original fracture. The gap in the fractured cortex had widened during immobilisation; on this side of the bone there had been no bony bridging before refracture (Fig. 1). Three other patients showed incomplete consolidation, two after a complete fracture, and one in whom the type of the original fracture was not known. Thus in 21 of the 25 patients who could be assessed there had been incomplete consolidation before the refracture (Table II).

Four patients apparently had complete healing of the primary fracture before refracture. One child with a torus fracture treated in plaster for three weeks sustained a refracture in a fall from a wall four weeks later. One other fell from a bicycle and another from an unknown height, both at ten weeks after the primary fracture. The fourth patient had a fall after 12 weeks. Refractures were seen at 4 to 32 weeks (mean 13.8) after the primary fracture; 12 patients refractured later than three months after the first injury.

The refracture was completely displaced in most patients; seven were incomplete and there was only one greenstick fracture. Four refractures were treated operatively by plating or intramedullary pins. Two other
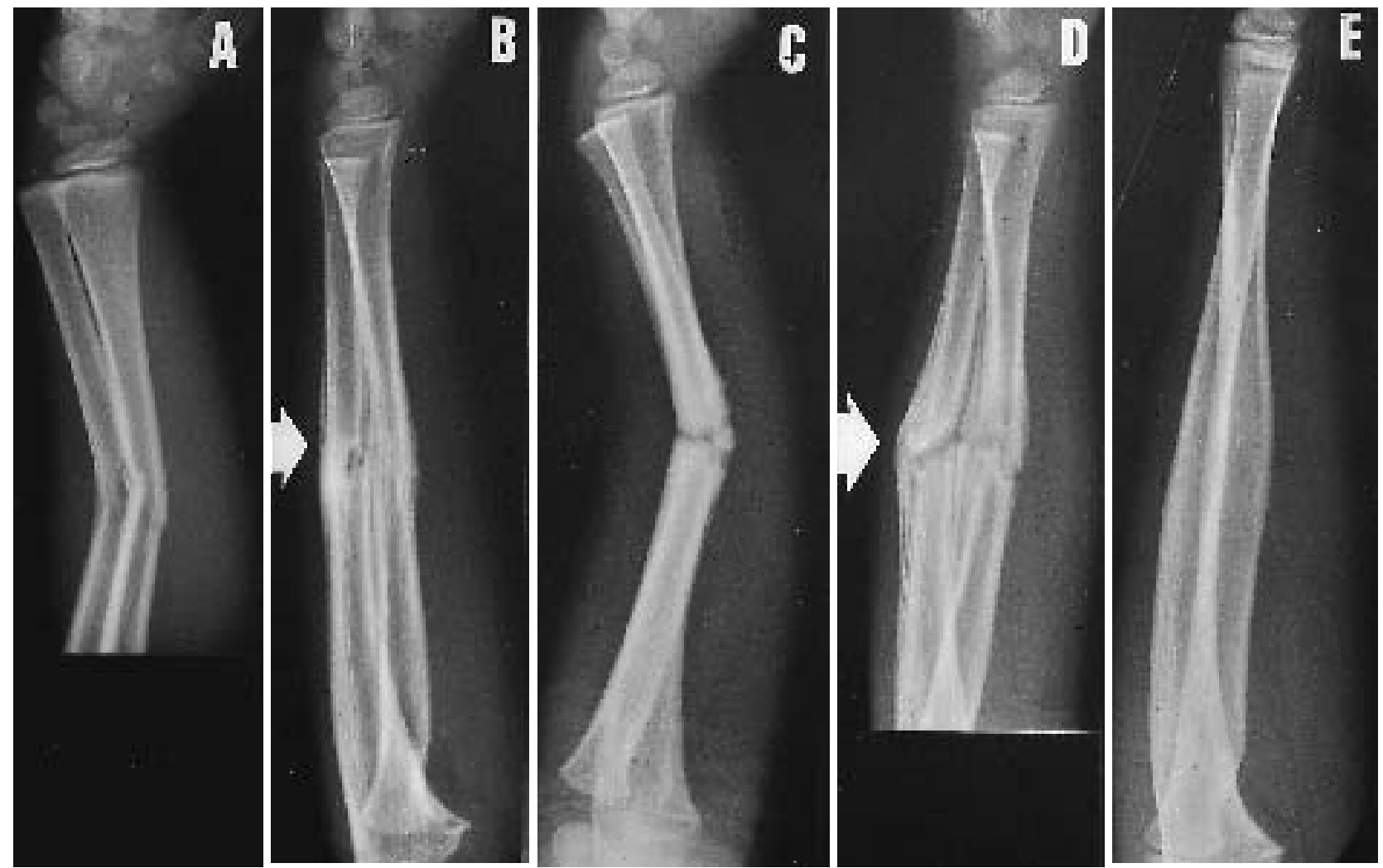

Fig. 2

A six-year-old boy had conservative therapy of a greenstick fracture (A). There was complete healing of only the radius (B arrow). A refracture (C) was treated conservatively and again showed complete healing of the radius, but with a persistent fracture gap on the ulna (D). Twenty-three weeks after the initial injury the patient had a second refracture (radiographs not available) which was also treated by plaster cast. Two years after the first injury the patient was asymptomatic with a free range of movement and an almost anatomical radiological result (E). 
Table I. Details and results of treatment of refracture of the forearm in 28 children

\begin{tabular}{|c|c|c|c|c|c|c|c|c|c|}
\hline \multirow[b]{2}{*}{ Case } & \multirow[b]{2}{*}{ Age } & \multicolumn{2}{|c|}{ Type of first fracture } & \multirow{2}{*}{$\begin{array}{l}\text { Delay* } \\
\text { (wk) }\end{array}$} & \multirow[b]{2}{*}{ Refracture } & \multirow{2}{*}{$\begin{array}{l}\text { Therapy } \\
\text { (wk) }\end{array}$} & \multirow{2}{*}{$\begin{array}{l}\text { Follow-up } \\
\text { (mth) }\end{array}$} & \multirow[b]{2}{*}{ Limitation ROM } & \multirow[b]{2}{*}{ Axial deviation } \\
\hline & & Radius & Ulna & & & & & & \\
\hline 1 & 9 & Greenstick & Greenstick & 30 & Ulna & POP 4 & 36 & None & Radius $15^{\circ}$ \\
\hline 2 & 5 & Greenstick & Greenstick & 14 & Both & 4 & 0 & & \\
\hline 3 & 13 & Greenstick & Intact & 18 & Radius & 6 & 20 & None & Radius $3^{\circ}$ \\
\hline 4 & 11 & Greenstick & Greenstick & 8 & Both & Plate & 15 & None & Radius $5^{\circ}$, ulna $5^{\circ}$ \\
\hline 5 & 5 & Intact & Greenstick & 7 & Ulna & 4 & 5 & None & None \\
\hline 6 & 4 & Greenstick & Greenstick & 8 & Both & 7 & 0 & & \\
\hline 7 & 13 & Greenstick & Intact & 15 & Radius & 4 & 9 & $\begin{array}{l}\text { Supination }-60^{\circ} \\
\text { Pronation }-20^{\circ}\end{array}$ & Radius $20^{\circ}$ \\
\hline 8 & 6 & Greenstick & Greenstick & 21 & Both & 5 & 53 & None & Radius $5^{\circ}$ \\
\hline 9 & 4 & Greenstick $\dagger$ & $\dagger$ & 4 & Radius & 6 & 141 & Supination $-5^{\circ}$ & Radius $5^{\circ}$ \\
\hline 10 & 8 & Greenstick & Greenstick & 10 & Both & 8 & 12 & None & Radius $5^{\circ}$, ulna $5^{\circ}$ \\
\hline 11 & 6 & Intact & Greenstick & 8 & Ulna & 6 & 139 & None & Ulna $5^{\circ}$ \\
\hline 12 & 10 & Complete & Greenstick & 14 & Both & 6 & 164 & None & Radius $3^{\circ}$ \\
\hline 13 & 11 & Greenstick & Intact & 30 & Both & 6 & 228 & $\begin{array}{l}\text { Supination }-60^{\circ} \\
\text { Pronation }-25^{\circ}\end{array}$ & Radius $18^{\circ}$ \\
\hline 14 & 13 & Greenstick & Greenstick & 12 & Both & Plate & 84 & None & None \\
\hline 15 & 7 & Greenstick & Greenstick & 10 & Both & 6 & 0 & & \\
\hline 16 & 12 & Complete & Greenstick & 22 & Both & 5 & 0 & & \\
\hline 17 & 7 & Greenstick & Greenstick & 16 & Both & 6 & 8 & Not evaluated & Radius $3^{\circ}$, ulna $8^{\circ}$ \\
\hline 18 & 4 & Greenstick & Intact & 6 & Radius & 4 & 108 & None & None \\
\hline 19 & 6 & Greenstick & Greenstick & 8 & Both & 8 & $23 \ddagger$ & None & Radius $5^{\circ}$ \\
\hline 20 & 12 & Complete & Intact & 22 & Radius & 8 & 24 & $\begin{array}{l}\text { Supination }-80^{\circ} \\
\text { Pronation }-55^{\circ}\end{array}$ & Radius $20^{\circ}$ \\
\hline 21 & 12 & Greenstick & Greenstick & 17 & Both & 8 & 123 & None & Ulna $5^{\circ}$ \\
\hline 22 & 13 & Complete & Complete & 10 & Both & 6 & 200 & $\begin{array}{l}\text { Supination }-10^{\circ} \\
\text { Pronation }-15^{\circ}\end{array}$ & Radius $15^{\circ}$, Ulna $15^{\circ}$ \\
\hline 23 & 9 & Subperiost & Intact & 4 & Radius & 4 & 20 & None & None \\
\hline 24 & 10 & Complete & Greenstick & 10 & Both & Plate & 34 & None & None \\
\hline 25 & 6 & Complete & Complete & 8 & Both & Plate & 0 & & \\
\hline 26 & 11 & $\dagger$ & $\dagger$ & 11 & Both & Wires & $49 \ddagger$ & None & Radius $8^{\circ}$ \\
\hline 27 & 7 & $\dagger$ & $\dagger$ & 32 & Both & Wires & 45 & Supination $-5^{\circ}$ & Radius $8^{\circ}$ \\
\hline 28 & 4 & $\dagger$ & $\dagger$ & 10 & Both & 4 & 30 & $\begin{array}{l}\text { Supination }-30^{\circ} \\
\text { Pronation }-15^{\circ}\end{array}$ & Radius $8^{\circ}$ \\
\hline
\end{tabular}

*between first fracture and refracture

$\dagger$ missing radiograph

$\ddagger$ two refractures 

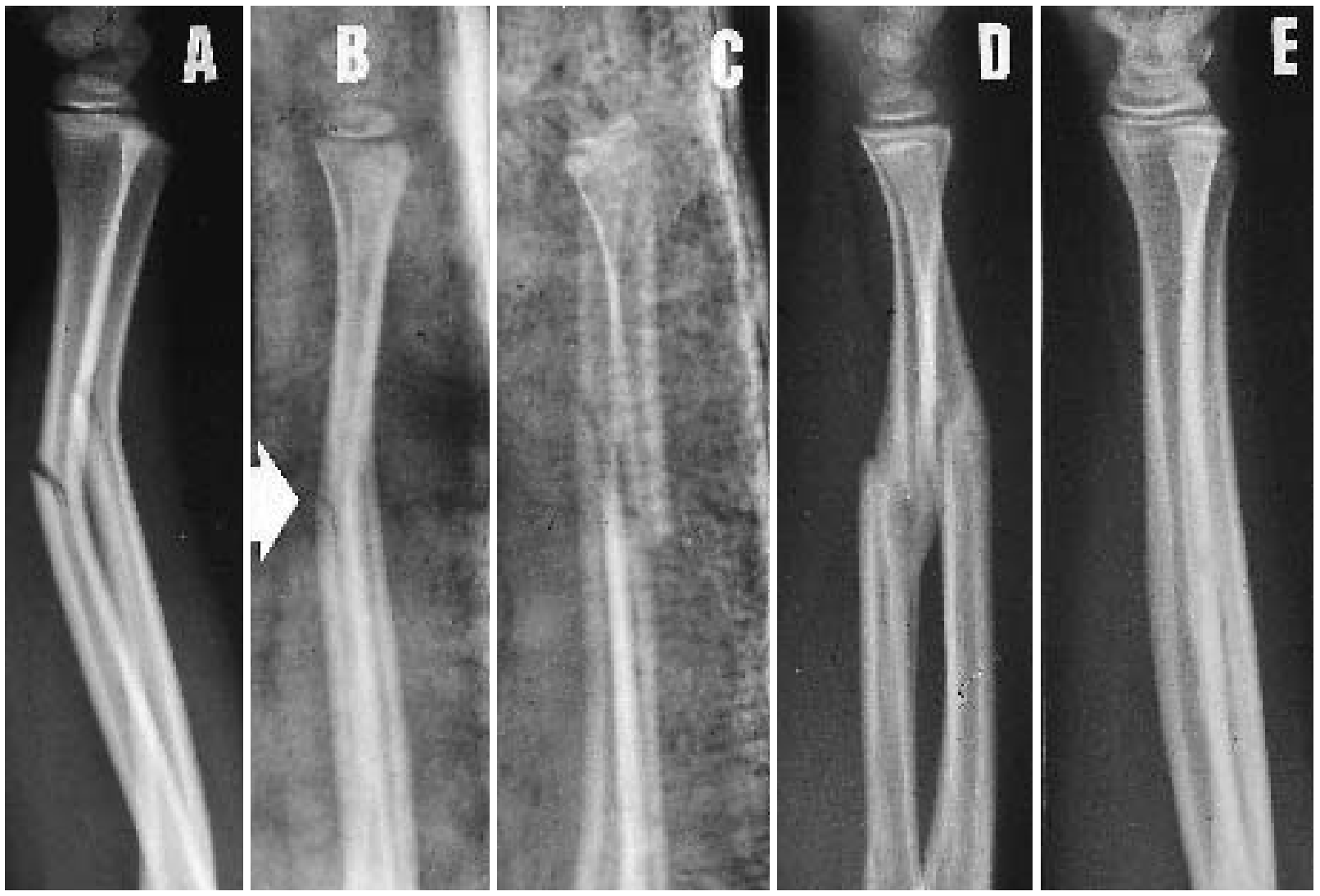

Fig. 3

A seven-year-old boy one week after injury (A); the fracture was completed (C) for persistent angulation (B arrow). The fracture healed by circular callus formation (D). The clinical and radiological outcome two years later was perfect (E).

patients with increasing angulation required secondary open reduction and internal fixation. There were no complications or problems with fracture healing after operation.

Conservative treatment of the refracture led to complete circular consolidation in all but five patients, one of whom had a second refracture (Fig. 2). One other patient sustained a second refracture with no obvious cause, but the radiographic series was incomplete and could not be evaluated.

\section{RESULTS}

A total of 23 patients was followed up for six months after refracture and 15 for two years or more.

At six months none had pain and movements were full with the exception of forearm rotation (Table I). Of the 17 treated conservatively, 11 had no limitation and three had less than $50 \%$ loss of forearm rotation. Three patients had a loss of over $50 \%$ as compared with the contralateral side due to an angulation of more than $10^{\circ}$. In the six patients operated on for the refracture, only one had angulation of only $8^{\circ}$, and only one had a supination deficit of $5^{\circ}$.

At two years after injury ten of the 11 patients reviewed after conservative treatment showed some angulation; this was greater than $10^{\circ}$ in five, and over $20^{\circ}$ in the other five. Three of the latter five patients had functionally impairing limitation of forearm rotation by more than $50 \%$, but only one of the five with angulation under $10^{\circ}$ had slight limitation of rotation. The three children with permanent functional impairment were all older than ten years of age at the time of injury, and their loss had not improved since the six-month review. After operative treatment angulation was under $10^{\circ}$ in two and absent in two. One patient had a loss of supination of $5^{\circ}$; the others were normal.

\section{DISCUSSION}

In children greenstick fractures of the forearm need special attention because the elasticity of the intact part of the cortex can impede healing and adversely affect conservative management. Blount, Schaefer and Johnson (1942) therefore proposed that this cortex be fractured, and Ogden (1990) agreed, although admitting that this may predispose to recurrent displacement. On refracture Blount et al (1942) stated that this is frequent during the first six months after trauma, and Gruber and von Laer (1979) showed a relationship between greenstick injuries and refracture, with an incidence of $34 \%$ of greenstick fractures in a series without refracture, but of $85 \%$ in those with refracture. Filipe et al (1979) discussed angular deviation as a cause of refracture. 
Table II. Causes of refracture of the forearm in 25 children

\begin{tabular}{ll}
\hline & Number \\
\hline $\begin{array}{l}\text { Greenstick fracture with incomplete } \\
\text { consolidation }\end{array}$ & 21 \\
Duration of fixation too short & 1 \\
Adequate second injury possible & 2 \\
No explanation & 1 \\
\hline
\end{tabular}

In our series of 25 refractures $84 \%$ showed incomplete consolidation, and this was almost always associated with angulation of a greenstick fracture. It is obvious that periosteal new bone formation is limited because of the relative stability provided by the intact section of cortex in greenstick fractures. The lack of compression forces impedes fracture healing, and there is often widening of the fracture gap during treatment. These gaps can heal spontaneously. We have seen this after primary fracture and refracture, but it is uncertain how long this takes; it may be from two to six months. We have seen no unhealed fracture gaps after six months.

Such a healing disturbance is rarely seen in complete primary fractures as the lack of stability in conservative treatment initiates the production of circular periosteal callus. Thus, refracture in complete fractures of the forearm is rare (Gruber and von Laer 1979). How can refracture of the forearm be prevented? If the observation is correct that all fracture gaps close spontaneously, protection by a splint for up to six months after injury should be curative. Lascombes et al (1988) immobilised fractures of the forearm in children for 90 days and recommended further immobilisation until remodelling of the cortex occurred in the case of partial healing.

It is assumed that correct and complete reduction of a greenstick fracture prevents incomplete healing by exerting intrafragmentary compression. Whether this can be done by a careful plaster technique (Ogden 1990) remains to be answered. The other method is to break the intact cortex thus producing an unstable fracture similar to a complete fracture (Fig. 3). Gruber and von Laer (1979) and Lascombes et al (1988) favour this method whereas von Laer (1996) advocates it only for all fractures with an angulation of more than $20^{\circ}$; in those with angulation of less than $20^{\circ}$ he suggests closure of the transverse fracture gap by wedging of the plaster.

We are not aware of any study which has prospectively evaluated the rate of refracture after different treatment methods of the primary fracture. Prevention of refracture means prevention of healing disturbances as the refracture is closely related to an incompletely healed primary fracture. Conservative treatment of the refracture gave very good or good results in 14 out of 17 patients. Three patients, however, had pronounced restriction of forearm rotation. Healing in a malaligned position should be avoided in patients older than ten years because of the limited potential for correction. If maintenance of reduction of a refracture is not possible, early open reduction and internal fixation is indicated. The disadvantage of operation is balanced by an almost ideal result.

The authors acknowledge and appreciate the contributions of D. Brass, MD, W. Jansky, MD, J Poigenfürst, MD and G. Straub, MD.

No benefits in any form have been received or will be received from a commercial party related directly or indirectly to the subject of the article.

\section{REFERENCES}

Arunachalam VS, Griffiths JC. Fracture recurrence in children. Injury 1975;7:37-40.

Blount WP, Schaefer AA, Johnson JH. Fractures of the forearm in children. JAMA 1942;120:111-6.

Filipe G, Dupont JY, Carlioz H. Recurrent fractures of both bones of the forearm in children. Chir Pediatr 1979;20:421-6.

Frinta J. Refrakturen im kindesalter. Zbl Chir 1957;82:1241-9.

Gruber R, von Laer LR. The etiology of the refracture of the forearm in childhood. Aktuelle Traumatol 1979;9:251-9.

Hager W, Ploberger E, Povacz P. Refrakturen nach kindlichen unterarmbrüchen. H. Unfallheilk 1989;201:418-20.

Lascombes P, Poncelet T, Lesur E, Prevot J, Blanquart D. Repeat fractures of the two forearm bones in children. Rev Chir Orthop 1988;74:Suppl 2:137-9.

Ogden JA. Skeletal injury in the child. Philadelphia, etc: W. B. Saunders Co, 1990.

Tischer W. Forearm fractures in childhood. Z Chir 1982;107:138-48.

von Laer L. Frakturen und luxationen im wachstumsalter. New York: Thieme Stuttgart, 1996. 